\title{
Evaluation of Onlay Island Flap Technique in Shallow Urethral Plate Hypospadiasis
}

\author{
Leily Mohajerzadeh, ${ }^{1, *}$ Alireza Mirshemirani, ${ }^{1}$ Mohsen Rouzrokh, ${ }^{1}$ Naser Sadeghian, ${ }^{1}$ Ahmad \\ Khaleghnejad-Tabari, ${ }^{1}$ Alireza Mahdavi, ${ }^{1}$ and Sareh Poorhasan ${ }^{1}$ \\ ${ }^{1}$ Pediatric Sugery Department, Mofid Children's Hospital, Iran University of Medical Sciences, Tehran, IR Iran \\ *Corresponding author: Leily Mohajerzadeh, Pediatric Sugery Department, Mofid Children's Hospital, Iran University of Medical Sciences, Tehran, IR Iran. E-mail: mohajerzadehl@ \\ yahoo.com
}

Received 2015 February 10; Revised 2015 October 6; Accepted 2015 October 16.

\begin{abstract}
Background: Hypospadias is one of the most common congenital genital anomalies in males that necessitates to be operated early in infancy (when 6 to 9 months old). On the other hand, hypospadias is a challenging field of pediatric urology with multiple reconstruction techniques. A perfect hypospadias repair is supposed to return urethral continuity with sufficient caliber, eradicate phallus curvature, and supply an acceptable appearance with low complications.

Objectives: This study aimed to evaluate the outcomes of using onlay island flap technique in the repair of hypospadias with shallow urethral plate.

Patients and Methods: In this prospective study within June 2012 to December 2013, we performed onlay island flap procedure to repair hypospadias with shallow urethral plate measuring less than 6 millimeter. This technique was selected for all types of hypospadiasis except subcoronal type. Nesbit's dorsal plication procedure was established for chordee. In cases with very small glans, urethroplasty was performed without glansplasty.

Results: Twenty three patients with mean age of 30 (range 10 - 60) months underwent onlay island flap repair; all had a shallow urethral plate $<6 \mathrm{~mm}, 3$ had a very small glans, and 18 had chordee. Meatus was located in distal shaft in 5 cases, mid shaft in 8, proximal in 6 and penoscrotal type in 4 patients. Chordee was corrected with Nesbit's dorsal plication in 16 cases. Complications were: meatal stenosis in 2 cases and urethrocutaneous fistula in 2 patients, all of which were repaired surgically. Mean follow up time was 13 (3-20) months. All cases that had glansplasty have excellent esthetic appearance.

Conclusions: This technique offers acceptable results regarding meatal stenosis, urethrocutaneous fistula and esthetic outcome.
\end{abstract}

Keywords: Onlay Island Flap, Hypospadias, Urethroplasty

\section{Background}

Hypospadias is one of the most common congenital genital anomalies in males that necessitates to be operated early in infancy (when 6 to 9 months old). On the other hand, hypospadias is a challenging field of pediatric urology with multiple reconstruction techniques. A perfect hypospadias repair is supposed to return urethral continuity with sufficient caliber, eradicate phallus curvature, and supply an acceptable appearance with low complications. Onlay preputial flap repair was introduced by Duckett (1) in 1987.

\section{Objectives}

In this study we are planning to assess objectively this skillful technique for complications such as fistula, dehiscence, recurrent ventral curvature, meatal stenosis, diverticulum and urethral stricture.

\section{Patients and Methods}

From June 2012 to December 2013 onlay island flap was performed to repair hypospadias with shallow urethral plate measuring less than 6 millimeter. This technique was selected for all types of hypospadiasis except subcoronal. Island flap onlay urethroplasty was performed based on the unique introduction by Duckett (1). In all cases glans penis is injected with 1:200,000 epinephrine at the incision sites, by using $2.5 \times$ magnifying loupe for most cases. Ventral skin was incised with a U-shaped incision that preserved the urethral plate (Figure 1). A circumferential incision $5 \mathrm{~mm}$ proximal to the coronal margin was done. Then phallus was completely degloved to the corpus spongiosum to correct mild ventral curvature. Subsequently, an artificial erection was performed to notice remaining ventral curvature, which if present, was straightened by Nesbit's dorsal plication with 4.0 prolen at the 12 o'clock position. Cases with severe chor- 
dee that needed transect urethral plate underwent inlay genital graft from scrotal skin and onlay island flap urethroplasty was performed 6 months later. Then a rectangular flap $1 \mathrm{~cm}$ longer than the length of the urethral plate was harvested from the dorsal inner prepuce ventrally rotated and anastomosed to the urethral plate with a 6-o polydioxanone running suture over an 8 Fr Silastic Foley catheter (Figure 2 ) and a vascular pedicle flap was used to cover the suture line. Two lateral incisions were made along the urethral plate with deep dissection into the glanular wings except in cases with very small glans. After glansplasty the penile shaft skin was closed with a midline suture or with a transverse island skin flap in cases of significant ventral skin deficiency according to surgeon's preference (Figure 3). In cases with very small glans, urethroplasty was performed without glansplasty. The urethra was stented post operatively for 7 days. All patients were operated on by a unique surgical team. Sandwich dressing was established for all cases (Figures 4 and 5). The dressing was changed on day 2 post surgery and catheter removed on day 7 . Children under 2 years of age had a double nappy whereas older children had a collecting bag. Patients were visited at the time of catheter removal 2 weeks and then at 1, 3, 6 and 12 months postoperative. Regular weekly meatal dilatation was used only in patients with voiding difficulty that had an obvious tendency to stenosis and a narrow stream on visual observation. Yearly follow up was planned by uroflowmetry in toilet trained children. Type of hypospadiasis, type of ventral curvature repair, complication rate such as fistula, dehiscence, recurrent ventral curvature, meatal stenosis, diverticulum and urethral stricture, management of complications and number of reoperations were analyzed. Postoperative uroflowmetry pattern in toilet trained patients will be reported in future. Data were collected and processed using the commercially available software package (SPSS-20 for Windows).

\section{Results}

Twenty three patients with mean age of 30 (range 10 $60)$ months underwent onlay island flap repair; all had a shallow urethral plate $<6 \mathrm{~mm}, 3$ had a very small glans, and 18 had chordee. Meatus was located in distal shaft in 5 cases, mid shaft in 8, proximal in 6 and penoscrotal type in 4 patients. The flap was sutured completely to the urethral plate, except in the mentioned 3 cases that was left 1 $\mathrm{cm}$ distal to the tip of the glans, which was sutured to the edges of the glandular wings. Glansplasty was performed in all cases, except in mentioned 3 cases that were left 1 $\mathrm{cm}$ distal to the tip of the glans, which was sutured to the edges of the glandular wings. Chordee was corrected with Nesbit's dorsal plication in 16 cases. In 2 cases with severe chordee, the urethral plate was transected first, then underwent inlay genital graft from scrotal skin and onlay island flap urethroplasty was performed 6 months later. Following onlay flap repair 3 (13\%) boys had fistula (one in distal shaft and two in midshaft), of whom one case with distal fistula is under observation, while other 2 cases were repaired surgically without further complications. Meatal stenosis was seen in 2 (9\%) cases and underwent meatoplasty. Mean follow up time was 13 months (3 - 20 months). All cases that had glansplasty have acceptable voiding and satisfactory cosmetic esthetic result and appearance, except 3 patients who had no glansplasty.

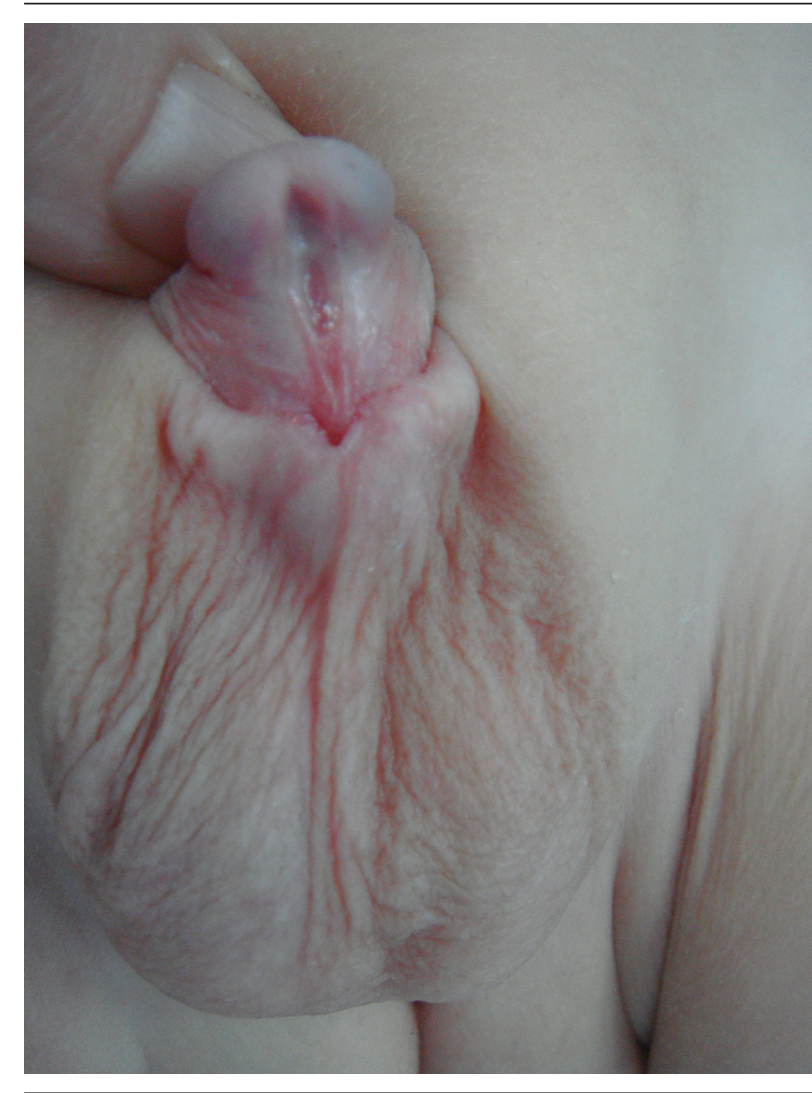

Figure 1. Midshaft Hypospadias

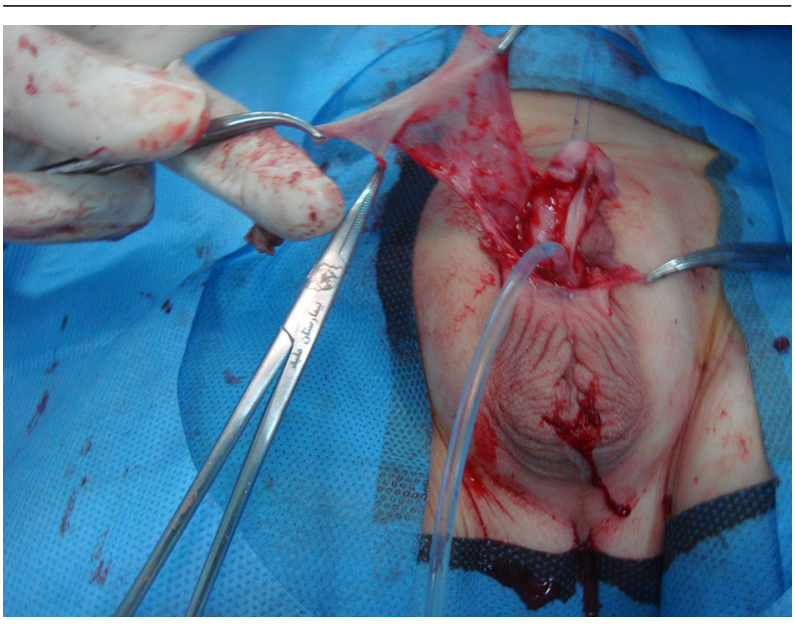

Figure 2. Onlay Flap 


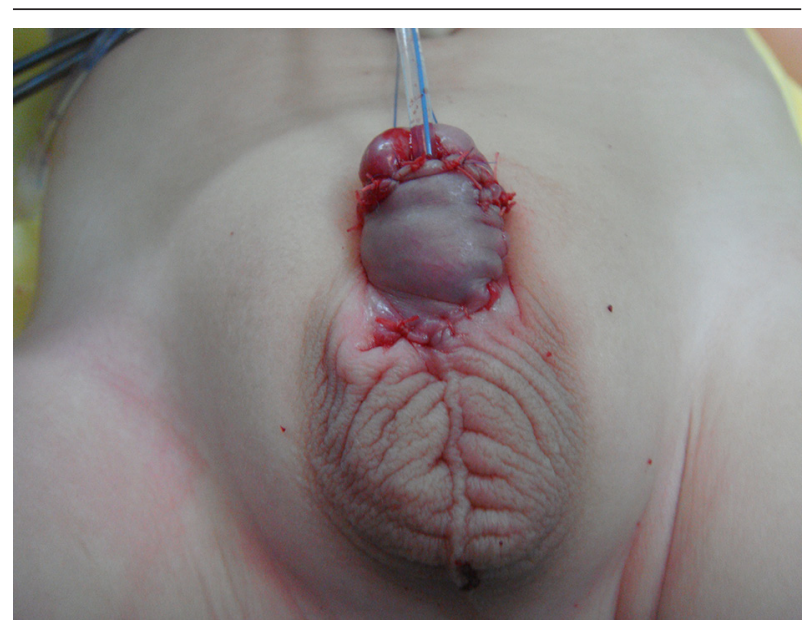

Figure 3. Completed Urethroplasty

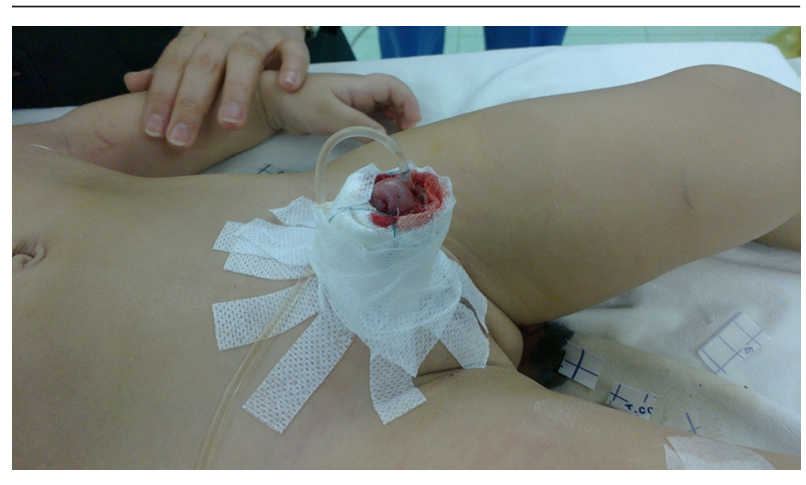

Figure 4. Sandwich Dressing

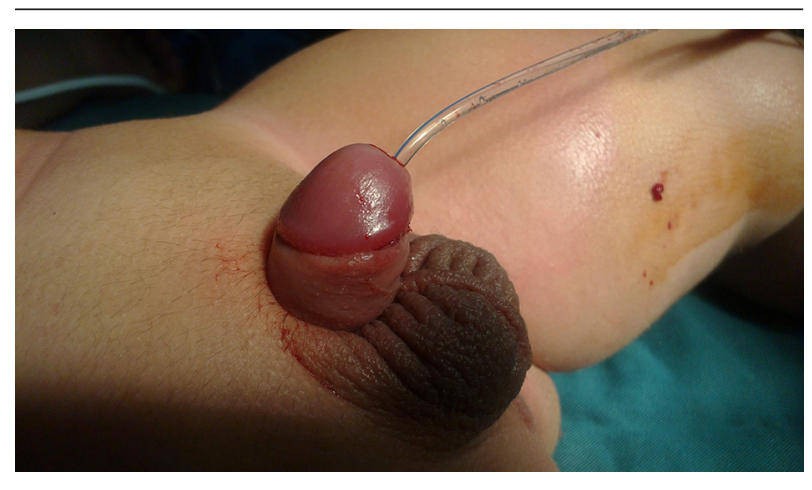

Figure 5. 7 Days After Surgery

\section{Discussion}

The purpose of primary hypospadias repair is to reach both beauty and functional normality. It necessitates the construction of a straight penis, with an acceptable caliber of neourethra that ends in a natural slit-like meatus (2). In hypospadias repair, there are many different techniques and modifications. Technique of repair is based on a number of variants such as degree of curvature, site of meatus, width of urethral plate and surgeon favorite. In onlay flap repair careful protection of the vasculature of the flap and prevention of overlapping suture lines generate a waterproof closure with minimum risk of postoperative fistula. Tubularized incised plate (TIP) is a common operation in hypospadias reconstruction, but our experience shows that risk of stricture and fistula in this method is relatively high and needs acceptable width of urethral plate for urethroplasty. However in Sozubir S et al.'s study, complications after TIP repair were equivalent to other current repairs, and with caution in technical details these complications could be decreased. The mentioned authors believed that this procedure regularly will generate a vertical meatus, and result in a normal aesthetic outcome (3).

Snodgrass et al. used TIP procedure for distal and proximal hypospadias. The main complication in their patients was fistula. Despite the use of a dartos flap in all cases, fistula occurred in 5\% of distal and $19 \%$ of proximal repairs (4). They used tubularized incised-plate urethroplasty for hypospadias reoperation but when it was employed in proximal hypospadias, they encountered a complication rate of $33 \%$ with $21 \%$ incidence of fistula and persistent chordee in some patients (4). In our study we had fistula in 3 (13\%) boys (one in distal shaft and two in midshaft). Results of hypospadias repair are very various in different centers as Cheng et al. (5) reported. A large multicenter series of patients with both distal and proximal hypospadias performed TIP repair with less than $1 \%$ occurrence of fistulas. They approximated the corpus spongiosum over the neourethra during proximal repair and protected neouretra with dartos layer and glans wings. In recent study the only parameter for selection of patients was urethral plate diameter less than 6 millimeter and type of hypospadias was not an effective factor.

Sarhan et al. (6) in a single-center experience with 500 cases reported TIP procedure as a reliable technique for management of both distal and proximal hypospadias in both primary and re-operative cases with a small rate of complications but urethral plate diameter was not mentioned.

Postoperative meatal/neourethral stenosis after TIP is common, so Shimotakahara (7) collected a dorsal inlay graft from the inner prepuce and sutured to midline incision of the urethral plate. In our study 2 cases with severe chordee needed to transect urethral plate who underwent inlay genital graft from scrotal skin and onlay island flap urethroplasty was performed 6 months later and both cases had acceptable results. Although TIP urethroplasty is a choice procedure in distal penile hypospadias for some surgeons, some others prefer to use onlay flap technique, particularly in cases of a small phallus with narrow plate or conical glans, which create tubularization difficult (7). In 1987, Elder (8) reported the first one-stage hypospadias repair using an onlay island flap, although the preputial island flap had long 
been done previously. It permits repair of distal and midshaft hypospadias. Elsayed et al. (9) evaluated the consequences of using a distally folded onlay flap in the repair of distal penile hypospadias in 36 patients, they had only two urethrocutaneous fistulas, and they used onlay flap for distal type. In our study it was used for all types except for subcoronal. Aboulhassan et al. (10) had a studied forty five boys with similar mid-penile hypospadias deformities and designed a comparative study between TIP and onlay preputial island flap and found no differences between the two techniques. Braga et al. (11) retrospectively analyzed patients with penoscrotal hypospadias. Based on surgeon favorite 35 children underwent TIP and 40 had onlay urethroplasty. They had complication rates of $60 \%$ for TIP and $45 \%$ for the onlay flap. Leslie et al. (12) used tunica vaginalis graft plus onlay preputial island flap in urethral reconstructive surgery in rabbits in one-stage for complex hypospadias with divided urethral plate. de Mattos e Silva et al. (13) compared three different urethroplasty techniques (onlay, buccal mucosa, Koyanagi type I) in severe hypospadias. Fistula occurred in 15\% in onlay group; $32 \%$ in buccal mucosa group, and $19.2 \%$ in Koyanagi cases. Patel et al.(14) introduced a technique called the split onlay skin flap, which had fistula in 6 patients. Subramaniam et al. (15) described several surgical techniques in hypospadiasis and their complications. Snodgrass (16) reported most of urethral complications are diagnosed at the first postoperative visit or within the first year after reconstruction. Glans dehiscence is usually apparent by 2 months, whereas most fistulas and other complications are found after 6 months.

\subsection{Conclusion}

In our experience with 23 patients the onlay flap hypospadias repair provided excellent cosmetic and functional results. The overall complication rate as well as the rate of postoperative urethrocutaneous fistula was minimal and compares favorably with rates reported by other authors, but need more long postoperative surveillance.

\section{Acknowledgments}

We would like to thank Ms Ghavam for typing the manuscript and Ms Hatefi for helping in research.

\section{Footnote}

Funding/Support:This study was financially supported by the office of the Vice Chancellor for Clinical Research of Mofid Children's Hospital.

\section{References}

1. Duckett Jr JW. Transverse preputial island flap technique for repair of severe hypospadias. 1980. J Urol. 2002;167(2 Pt 2):1179-82. [PubMed:11905895]

2. Manzoni G, Bracka A, Palminteri E, Marrocco G. Hypospadias surgery: when, what and by whom? BJU Int. 2004;94(8):1188-95. doi: 10.1046/j.1464-410x.2004.05128.x. [PubMed:15613162]

3. Sozubir S, Snodgrass W. A new algorithm for primary hypospadias repair based on tip urethroplasty. J Pediatr Surg. 2003;38(8):1157-61. [PubMed:12891485]

4. Snodgrass WT, Lorenzo A. Tubularized incised-plate urethroplas ty for proximal hypospadias. BJU Int. 2002;89(1):90-3. [PubMed 11849169]

5. Cheng EY, Vemulapalli SN, Kropp BP, Pope JC, Furness PD, Kaplan WE, et al. Snodgrass hypospadias repair with vascularized dartos flap: the perfect repair for virgin cases of hypospadias? J Urol. 2002;168(4 Pt 2):1723-6. doi: 10.1097/01.ju.0000026940.33540.31. [PubMed:12352344]

6. Sarhan OM, El-Hefnawy AS, Hafez AT, Elsherbiny MT, Dawaba ME, Ghali AM. Factors affecting outcome of tubularized incised plate (TIP) urethroplasty: single-center experience with 500 cases. $J$ Pediatr Urol. 2009;5(5):378-82. doi: 10.1016/j.jpurol.2009.02.204. [PubMed:19632898]

7. Shimotakahara A, Nakazawa N, Wada A, Nagata S, Koga H, Takahashi T, et al. Tubularized incised plate urethroplasty with dorsal inlay graft prevents meatal/neourethral stenosis: a single surgeon's experience. J Pediatr Surg. 2011;46(12):2370-2. doi: 10.1016/j. jpedsurg.2011.09.033. [PubMed: 22152884]

8. Elder JS, Duckett JW, Snyder HM. Onlay island flap in the repair of mid and distal penile hypospadias without chordee. J Urol. 1987;138(2):376-9. [PubMed:3599258]

9. Elsayed ER, Khalil S, Abd Samad K, Abdalla MM. Evaluation of distally folded onlay flap in repair of distal penile hypospadias. J Pediatr Urol. 2012;8(1):103-7. doi: 10.1016/j.jpurol.2010.09.008. [PubMed: 20889383]

10. Aboulhassan MA, Bahaaeldin KH, Mansour OM, Ziada AM. Com parative study between the tubularized incised plate urethroplasty and single faced onlay preputial island flap in the management of mid-penile hypospadias. Ann Pediatr Surg . 2005;1(1):32-37.

11. Braga LH, Pippi Salle JL, Lorenzo AJ, Skeldon S, Dave S, Farhat WA, et al. Comparative analysis of tubularized incised plate versus onlay island flap urethroplasty for penoscrotal hypospadias. J Urol. 2007;178(4 Pt 1):1451-6. doi: 10.1016/j.juro.2007.05.170. [PubMed: 17706707]

12. Leslie B, Barboza LL, Souza PO, Silva PS, Delcelo R, Ortiz V, et al Dorsal tunica vaginalis graft plus onlay preputial island flap urethroplasty: experimental study in rabbits. J Pediatr Urol. 2009;5(2):93-9. doi: 10.1016/j.jpurol.2008.09.003. [PubMed: 19010086]

13. de Mattos e Silva E, Gorduza DB, Catti M, Valmalle AF, Demede D, Hameury F, et al. Outcome of severe hypospadias repair using three different techniques. J Pediatr Urol. 2009;5(3):205-11. doi: 10.1016/j.jpurol.2008.12.010. [PubMed:19201261]

14. Patel RP, Shukla AR, Leone NT, Carr MC, Canning DA. Split onlay skin flap for the salvage hypospadias repair. J Urol. 2005;173(5):1718-20. doi: 10.1097/01.ju.0000154609.14084.5c. [PubMed:15821567]

15. Subramaniam R, Spinoit AF, Hoebeke P. Hypospadias repair: an overview of the actual techniques. Semin Plast Surg. 2011;25(3):206-12. doi:10.1055/s-0031-1281490. [PubMed: 22851912]

16. Snodgrass W, Villanueva C, Bush NC. Duration of follow-up to diagnose hypospadias urethroplasty complications. J Pediatr Urol. 2014;10(2):208-11. doi: 10.1016/j.jpurol.2013.11.011. [PubMed: 24439629] 